\title{
PENGARUH HARGA, ONLINE CUSTOMER REVIEW DAN FASILITAS TERHADAP TINGKAT HUNIAN DI PT. KARYA CIPTA PESONA (ARYADUTA MEDAN)
}

\author{
Sri Rezeki ${ }^{1}$, Ninie $^{2}$ \\ Program Studi Manajemen \\ Sekolah Tinggi Ilmu Ekonomi Eka Prasetya \\ audrey.th@gmail.com \\ niniefamm@gmail.com
}

\begin{abstract}
The purpose of this study is to determine the effect of the Price, Online Customer Review and Facilities on Occupancy Rate at PT. Karya Cipta Pesona (Aryaduta Medan). The research methodology used is descriptive quantitative method, the unit of analysis in this study is PT. Karya Cipta Pesona (Aryaduta Medan) and its observation unit are guests from PT. Karya Cipta Pesona (Aryaduta Medan). The population in this study were guests from PT. Karya Cipta Pesona (Aryaduta Medan) as many as 61,565 respondents. The technique of determining the number of samples used in this study is the Slovin formula and amounts to 100 respondents. The research method used is by data collection techniques through library research and field research conducted systematically based on research objectives. The analytical method used to solve problems and prove hypotheses is descriptive analysis, regression analysis. The results of the t test show that the price variable has a positive and significant effect on Room Occupancy at PT. Karya Cipta Pesona (Aryaduta Medan), Online Customer Review variable has a positive and significant effect on Room Occupancy at PT. Karya Cipta Pesona (Aryaduta Medan), and Facilities variables have a positive and significant effect on Room Occupancy at PT. Karya Cipta Pesona (Aryaduta Medan),. The results of independent variables Price, Online Customer Review and Facilities simultaneously influence the dependent variable Occupancy. The determination coefficient test results $\left(R^{2}\right)$ indicate that $65.90 \%$ of Occupancy variables are influenced by Price, Online Customer Review and Facilities variables, while the remaining $34.10 \%$ is explained by the influence of other factors or variables outside the model such as Service Quality and Satisfaction.
\end{abstract}

Keywords: Price, Online Customer Review, Facilities, Occupancy

\section{PENDAHULUAN}

Pada masa Romawi telah muncul rumah-rumah penginapan yang disebut "mansiones" di sepanjang jalan-jalan utama kota yang disewakan untuk para pelancong. Mansiones sendiri berarti flat. Antara satu mansiones dengan mansiones lainnya biasanya berjarak hingga puluhan kilometer. Pada masa-masa selanjutnya, ketika bepergian jauh semakin banyak dilakukan orang, khususnya untuk kegiatan dagang, ziarah, maupun aktivitas militer, rumah-rumah penginapan pun semakin banyak didirikan.

Di sepanjang jalur-jalur perdagangan dunia dan kota-kota kuno, seperti Yerusalem, Baghdad, Makkah, 
Cordoba, Roma, maupun Konstantinopel, ada banyak penginapan yang didirikan. Perbatasan antara Barat dan Timur dalam Perang Salib (dimulai 1096 M) berperan penting dalam melahirkan kota-kota baru di sepanjang Asia Kecil, yaitu wilayah Turki yang memanjang ke Syiria dan akhirnya Palestina. Di sepanjang jalur ini, ada banyak penginapan yang diperuntukkan bagi para prajurit dan para peziarah yang ingin berkunjung ke Palestina. Bahkan, pada Abad Pertengahan, kehadiran rumah-rumah penginapan ini mendapat dukungan dari otoritas gereja untuk kepentingan para peziarah.

Pada perkembangan selanjutnya, yaitu setelah Abad Pertengahan, rumahrumah penginapan tidak hanya menyediakan fasilitas penginapan, tetapi juga mulai melengkapinya dengan fasilitas pendukung lainnya, semacam bar, salon, dan kedai makanan. Jumlah kamar pun mulai diperbanyak hingga mencapai puluhan. Inilah yang kemudian menjadi cikal bakal lahirnya hotel dalam makna sebenarnya, yaitu gedung tempat singgah yang menyediakan fasilitas lengkap.

Pada abad ke-20, khususnya setelah berakhirnya Perang Dunia I, jumlah hotel semakin meningkat seiring perkembangan alat-alat transportasi massal dan berkembangnya bisnis travel. Hotel-hotel baru ini banyak didirikan di sekitar pusat-pusat bisnis. Hal lain yang turut mempengaruhi perkembangan industri hotel adalah berkembangnya dunia pariwisata yang kemudian melahirkan hotel-hotel resort yang menawarkan paket penginapan sekaligus akomodasi. Pada masa ini, sejak tahun 1920-an, sekolah-sekolah perhotelan pun mulai bermunculan di banyak tempat. Pada masa berlangsungnya Perang Dunia ke-2, dan masa-masa sesudahnya, bisnis perhotelan berkembang pesat. Akan tetapi, pada masa itu hampir tidak ada hotel baru yang dibangun.

Para pengelola lebih memilih untuk mengembangkan hotel yang ada, baik dari segi fasilitas, kualitas pelayanan, dan manajemen, termasuk berpindahnya kepemilikan hotel dari pribadi ke dalam sebuah korporasi. Dalam perkembangan selanjutnya, industri hotel-hotel besar di Amerika mulai melebarkan sayapnya ke luar negeri dengan menggunakan sistem franchise. Lahirlah jaringan hotel-hotel besar di bawah sebuah korporasi besar, seperti Hilton, Hyatt, JW Marriots, dan sebagainya.

Di Indonesia, Hotel Indonesia adalah hotel bintang 5 pertama yang dibangun di Jakarta. Hotel ini diresmikan pada tanggal 5 Agustus 1962 oleh Presiden RI Pertama Soekarno untuk menyambut Asian Games IV tahun 1962. Bangunan Hotel Indonesia dirancang oleh arsitek Abel Sorensen dan Istrinya Wendy dari Amerika serikat. Saat ini Hotel Indonesia telah mengalami pemugaran dan berubah nama menjadi Hotel Indonesia Kempinski.

Melanjutkan pembangunan Hotel Indonesia dan Sejak semakin terkenalnya nama Bali di dunia Internasional, maka Pada tahun 1963, dibangun pula Hotel Bali Beach yang merupakan hotel tertinggi di Bali karena setelahnya tidak ada lagi hotel dibali yang lebih tingi dari empat lantai, menyusul diresmikannya Pelabuhan Udara Ngurah Rai sebagai pelabuhan internasional, tiga tahun berselang.

Bisa dikatakan bahwa perkembangan bisnis perhotelan dan pariwisata di Indonesia mengalami peningkatan yang cukup signifikan. Ini bisa dilihat berdasarkan meningkatnya jumlah kunjungan wisatawan di Indonesia dan pertumbuhan industri 
pariwisata termasuk bertumbuhnya jumlah hotel di Indonesia. Memang selama ini Jakarta, Yogyakarta dan Bali menjadi barometer pariwisata namun sebenarnya banyak wilayah di Indonesia yang mengalami pertumbuhan pariwisata yang terbilang pesat seperti Sulawesi Utara, Papua, dan beberapa wilayah lainnya juga telah mengalami pertumbuhan yang signifikan dalam bidang pariwisata.Banyaknya investor yang melakukan penetrasi dengan membangun hotel berjejaring juga bisa menjadi indikator bersama dengan tingkat hunian masing-masing hotel tersebut.

Aryaduta Medan adalah sebuah hotel berbintang lima di Medan yang mulai beroperasi sejak tahun 2007, dengan total 195 kamar, 8 meeting room, dan 1 restoran dengan beberapa outlet. Beralamat di Jalan Kapten Maulana Lubis No. 8, kamar yang tersedia ada dari tipe Deluxe, Premier Deluxe, Grand Deluxe, Pool Terrace, Junior Suite, Executive Suite, Business Suite, dan Aryaduta Suite. Untuk fasilitas yang tersedia, Aryaduta Medan menyediakan layanan concierge 24 jam,in-house Fitness Center, Courtyard Pool, Free Wi$F i$. Semua fasilitas tersebut dapat dinikmati dengan gratis oleh setiap tamu yang menginap di Aryaduta Medan. Sedangkan untuk fasilitas berbayar Aryaduta Medan ada layanan laundry, inroom massage, ruangan rapat (meeting room), dan layanan sewa mobil.

Salah satu fasilitas unggulan Aryaduta Medan adalah Courtyard Pool, yang memiliki view yang bagus, selain itu ada juga kamar yang memiliki akses langsung ke kolam renang, yaitu tipe Pool Terrace. Pool Terrace sesuai namanya memiliki teras diluar kamar, dan mempunyai akses langsung ke kolam renang, membuatnya menjadi kamar favorit di Aryaduta Medan. Selain itu, selain di Aryaduta Medan, kamar sejenis
Pool Terrace tidak terdapat di hotel kompetitor lainnya.

Untuk kompetitor, Aryaduta Medan bersaing secara langsung dengan beberapa hotel ternama, seperti Grand Aston City Hall, Cambridge Hotel, Hotel Santika Premiere Dyandra, dan Grand Mercure. Biasanya hotel tersebut disebut direct competitor, ini di lihat dari kelas hotel, harga dan lokasi hotel yang semuanya berada di dekat Aryaduta Medan.

Dalam menjual kamar, hotelhotel pada saat ini umumnya telah mendaftarkan hotel pada Online Travel Agent. Peneliti melihat kuatnya persaingan bisnis yang ada dengan banyaknya pelaku bisnis perhotelan kini, termasuk juga jarak antara kompetitor yang tidak begitu jauh satu sama lain. Hal ini membuat Aryaduta Medan harus meningkatkan kualitas dalam berbagai aspek, yaitu produk dan fasilitas. Aryaduta Medan merupakan perusahaan yang bergerak dalam bidang perhotelan, dan yang dijual adalah berupa jasa penginapan (kamar) dan makanan (restoran).

Pada saat ini, dapat dikatakan hampir 30\% dari kamar yang dipenuhi setiap malamnya adalah berasal dari $E$ commerce yang dijalankan oleh Aryaduta Medan, contohnya seperti Agoda, Traveloka, Aryaduta Website,dll. Dan sangat mudah untuk memberikan ulasan pada hotel yang kita kunjungi di laman Online Travel Agent. Pada saat ini, biasanya calon tamu akan mencari hotel dengan Rating yang bagus pada laman Online Travel Agent.

Online Customer Review merupakan bagian dari Electronic Word of Mouth (eWOM), yaitu merupakan pendapat langsung dari seseorang dan bukan sebuah iklan. Review adalah salah satu dari beberapa faktor yang 
menentukan keputusan pembelian seseorang, menunjukkan bahwa orang dapat mengambil jumlah review sebagai indikator popularitas produk atau nilai dari suatu produk yang akanmempengaruhi kemauan untuk membeli suatu produk. Dalam hal ini, penting sekali bagi Aryaduta Medan untuk tetap mempertahankan rating yang bagus pada Online Travel Agent dengan cara mempertahankan kualitas produk dan jasa kepada tamu.

Aryaduta Medan biasa mendapatkan review dari tamu dari Traveloka, Agoda, Pegipegi, dan masih banyak lagi. Tamu yang telah menginap akan member nilai kepuasan dari berbagai aspek seperti pelayanan, kebersihan, fasilitas, harga,dll. Dari review, Aryaduta Medan dapat mengetahui kekurangannya agar dapat melayani tamu dengan lebih baik lagi. Bukan hanya Aryaduta, para direct competitornya pun memperhatikan kepuasan tamu dari review-review yang diperoleh dari Online Travel Agent. Dalam mengukur tingkat review tersebut, Aryaduta Medan dan sejumlah hotel di Medan menggunakan Review Pro, yaitu suatu situs yang mengumpulkan semua review yang dikirimkan pada semua tamu yang menginap di hotel. Angka yang dihasilkan oleh Review Pro disebut Global Review Index, yang diartikan sebagai angka review yang diberikan konsumen terhadap hotel, dapat dikatakan juga sebagai reputasi hotel tersebut.

Tingkat hunian (occupancy) adalah presentase dari kamar yang terisi atau yang tersewakan kepada tamu dibandingkan dengan jumlah keseluruhan kamar yang ada disewakan yang diperhitungkan dalam jangka waktu dari hari, bulanan, atau tahunan. Dalam kompetisi kepenghunian (occupancy) persaingan akan memperkirakan kinerja operasi bulanan atau tahunan hotel.
Kinerja dapat di ukur dari segi hunian persen dan tarif kamar rata-rata hunian.

\section{TELAAH PUSTAKA DAN HIPOTESIS}

\section{Tingkat Hunian}

Menurut Suartana (2006:4), Tingkat Hunian adalah jumlah kamar yang terjual atau tersewa pada suatu waktu tertentu, dan menurut Suartana (2006:4), ada 5 indikator Tingkat Hunian, antara lain: 1) Lokasi hotel, 2) Fasilitas hotel, 3) Pelayanan kamar, 4) Harga kamar, dan 5) Promosi.

\section{Harga}

Menurut Kotler dan Amstrong (2012:345), Harga adalah sejumlah uang yang ditagih atas suatu produk atau jasa, atau jumlah semua nilai yang diberikan oleh pelanggan untuk mendapatkan keuntungan dari memiliki atau menggunakan suatu produk atau jasa, dan menurut Kotler dan Amstrong (2012:314), ada 4 indikator Harga antara lain: 1) Keterjangkauan harga, 2) Kesesuaian harga dengan kualitas, 3) Daya saing harga, dan 4) Kesesuaian harga dengan manfaat.

\section{Online Customer Review}

Menurut Ahmad Farki (2016), Review merupakan bagian dari Electronic Word of Mouth (eWOM), yaitu merupakan pendapat langsung dari seseorang dan bukan sebuah iklan. Review adalah salah satu dari beberapa faktor yang menentukan keputusan pembelian seseorang, menunjukkan bahwa orang dapat mengambil jumlah review sebagai indikator popularitas produk atau nilai dari suatu produk yang akan mempengaruhi kemauan untuk membeli suatu produk, dan menurut Ahmad Farki (2016), ada 3 indikator Online Customer Review, antara lain: 1) Perceived Usefulness, 2) Perceived Enjoyment, dan 3) Perceived Control. 
Berikut pengujian hipotesis penelitiannya:

$\mathrm{H}_{1}$ : Terdapat pengaruh positif dan signifikan Harga terhadap Tingkat Hunian

$\mathrm{H}_{2}$ : Terdapat pengaruh positif dan signifikan Online Customer Review terhadap Tingkat Hunian

$\mathrm{H}_{3}$ : Terdapat pengaruh positif dan signifikan Fasilitas terhadap Tingkat Hunian

$\mathrm{H}_{4}$ : Terdapat pengaruh positif dan signifikan Harga, Online Customer Review dan Fasilitas terhadap Tingkat Hunian

Kerangka teoritis dalam penelitian ini akan menjelaskan hubungan antara masing-masing variabel dapat dilihat pada Gambar 1.

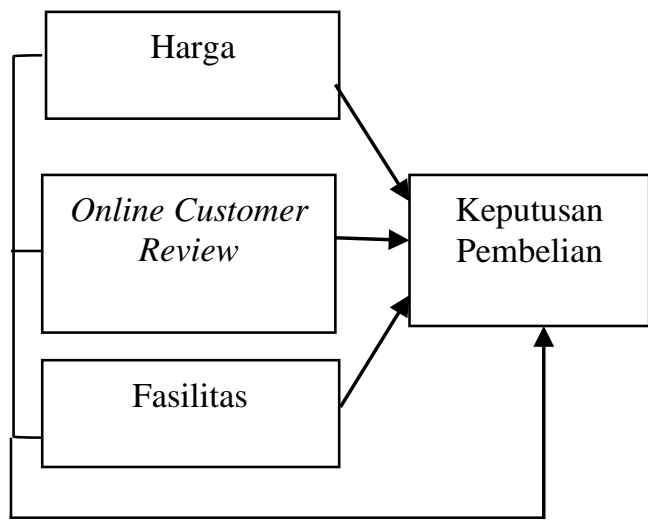

Gambar 1. Kerangka Pemikiran

\section{METODOLOGI PENELITIAN \\ Lokasi Penelitian}

Penelitian ini dilakukan di Aryaduta Medan yang berada di jalan Kapten Maulana Lubis No. 8 Medan.

\section{Populasi dan Sampel}

Dalam menentukan populasi penelitian, peneliti akan mengambil sebanyak 61.565 orang tamu yang menginap di Aryaduta Medan.

Teknik pengambilan sampel penelitian ini menggunakan rumus Slovin. Sehingga sampel penelitian ini sebanyak 100 responden.

\section{Teknik Pengumpulan Data}

Metode pengumpulan data yang digunakan dalam penelitian ini adalah metode angket (kuesioner terstruktur) yang diberikan kepada responden, yaitu tamu pada PT. Karya Cipta Pesona (Aryaduta Medan). Yang dilakukan peneliti untuk mendapatkan data yaitu dengan cara penyebaran angket. Metode angket menurut Sugiyono (2018:142) merupakan teknik pengumpulan data yang dilakukan dengan cara memberi seperangkat pertanyaan atau pernyataan tertulis kepada responden untuk menjawabnya.

\section{Teknik Analisis Data}

Dalam penelitian ini, teknik analisis regresi linier berganda digunakan. Analisis regresi linear berkaitan dengan studi mengenai ketergantungan variabel dependen (terikat) dengan variabel independen (bebas), dengan tujuan untuk mengestimasi dan memprediksi rata-rata populasi atau nilai rata-rata variabel dependen berdasarkan nilai independen yang diketahui. Analisis linear berganda digunakan untuk mengetahui pengaruh Harga $\left(\mathrm{X}_{1}\right)$, Online Customer Review $\left(\mathrm{X}_{2}\right)$, dan Fasilitas $\left(\mathrm{X}_{3}\right)$ terhadap Tingkat Hunian (Y). Perhitungan dapat dirumuskan dengan formula sebagai berikut:

$$
Y=\alpha+\beta_{1} X_{1}+\beta_{2} X_{2}+\beta_{3} X_{3}+e
$$




\section{HASIL DAN PEMBAHASAN Karakteristik Responden \\ Karakteristik responden} berdasarkan usia yaitu responden berusia 17-22 tahun berjumlah 11 orang (11\%), responden berusia 23-28 tahun berjumlah 45 orang $(45 \%)$, responden berusia $29-34$ tahun berjumlah 25 orang (25\%), dan responden berusia $>34$ tahun berjumlah 19 orang (19\%). Hal ini menjelaskan bahwa secara keseluruhan usia responden adalah 23-28 tahun karena memiliki persentase yang lebih tinggi.

Karakteristik responden berdasarkan pekerjaan yaitu responden yang berprofesi sebagai mahasiswa berjumlah 13 orang (13\%), responden yang berprofesi sebagai karyawan berjumlah 35 orang $(35 \%)$, responden yang berprofesi sebagai ibu rumah tangga berjumlah 23 orang (23\%), dan responden yang berprofesi sebagai lainnya berjumlah 29 orang (29\%). Hal ini menjelaskan bahwa secara keseluruhan responden yang berprofesi sebagai karyawan karena memiliki persentase yang lebih tinggi.

Karakteristik responden berdasarkan reservasi kamar yaitu responden yang melakukan reservasi individual berjumlah 43 orang (43\%), responden yang melakukan corporate berjumlah 28 orang (28\%), responden yang melakukan reservasi travel agent berjumlah 14 orang (14\%), dan responden yang melakukan reservasi online travel agent berjumlah 15 orang $(15 \%)$. Hal ini menjelaskan bahwa secara keseluruhan responden yang melakukan reservasi kamar individual karena memiliki persentase yang lebih tinggi.

\section{Uji Validitas dan Uji Reliabilitas}

Menurut Ghozali (2018), mengukur validitas dapat dilakukan dengan cara melakukan korelasi antar skor butir pertanyaan dengan total skor konstruk atau variabel.

Penggunaan item-item sebagai indikator-indikator dari data variabel

penelitian mensyaratkan adanya suatu pengujian konsistensi melalui uji reliabilitas, sehingga data yang digunakan tersebut benar-benar dapat dipercaya. Hasil uji Validitas dan Reliabilitas akan disajikan pada tabel 1 dan tabel 2 .

Tabel 1. Hasil Uji Validitas

\begin{tabular}{llll}
\hline No & Pernyataan & Variabel & $\mathrm{r}_{\text {hitung }}$ \\
\hline 1 & H-1 & & 0,885 \\
2 & H-2 & Harga & 0,631 \\
3 & H-3 & & 0,833 \\
4 & H-4 & & 0,822 \\
\hline 1 & OCR-1 & Online & 0,919 \\
2 & OCR-2 & Customer & 0,762 \\
3 & OCR-3 & Review & 0,947 \\
\hline 1 & F-1 & & 0,740 \\
2 & F-2 & & 0,671 \\
3 & F-3 & & 0,745 \\
4 & F-4 & Fasilitas & 0,465 \\
5 & F-5 & & 0,611 \\
6 & F-6 & & 0,461 \\
\hline 1 & TH-1 & & 0,918 \\
2 & TH-2 & Tingkat & 0,764 \\
3 & TH-3 & Hunian & 0,907 \\
4 & TH-4 & & 0,833 \\
5 & TH-5 & & 0,878 \\
\hline Sur & &
\end{tabular}

Sumber : Data Primer (Diolah), 2019

Dari tabel 1 diperoleh nilai $\mathrm{r}_{\text {hitung }}$ dari masing-masing item pernyataan untuk setiap variabel diperoleh di atas 0,361 sehingga dapat dikatakan pernyataan yang digunakan dalam variabel penelitian dikatakan validitas.

Tabel 2. Hasil Uji Reliabilitas

\begin{tabular}{llcc}
\hline No & Variabel & $\begin{array}{c}\text { Jumlah } \\
\text { Item }\end{array}$ & $\begin{array}{c}\text { Cronbach's } \\
\text { Alpha }\end{array}$ \\
\hline 1 & Harga & 4 & 0,807 \\
\hline 2 & $\begin{array}{l}\text { Online } \\
\text { Customer } \\
\text { Review }\end{array}$ & 3 & 0,847 \\
\hline 3 & Fasilitas & 6 & 0,662 \\
\hline 4 & $\begin{array}{l}\text { Tingkat } \\
\text { Hunian }\end{array}$ & 5 & 0,911 \\
\hline Sumber : Data Primer (diolah), 2019
\end{tabular}


Dari tabel 2 juga diperoleh dari masing-masing variabel di Cronbach's Alpha tidak dibawah 0,6 sehingga dapat dinyatakan reliable. distribusi kumulatif dari distribusi normal.

\section{Uji Asumsi Klasik \\ Uji Normalitas}

Uji normalitas bertujuan untuk menguji apakah dalam model regresi variabel pengganggu atau residual memiliki distribusi normal. Ada dua cara untuk mendeteksi apakah residual berdistribusi normal atau tidak, yaitu dengan analisis grafik dan uji statistik.

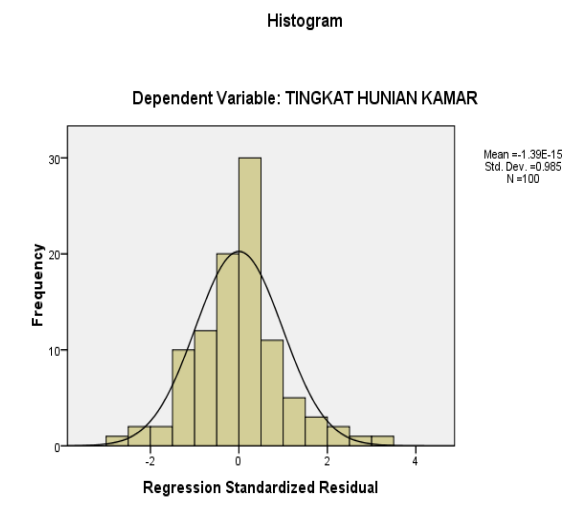

Sumber : Data Primer (diolah), 2019

Gambar 2. Grafik Histogram

Dari Gambar 2 dapat dilihat bahwa data tegak lurus di atas angka 0 , tidak melenceng ke kiri dan ke kanan, maka model regresi dianggap memenuhi asumsi normalitas.

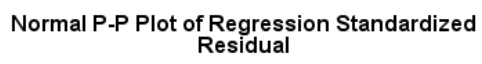
Normal P-P Plot of Regression Standardized
Residual

Dependent Variable: TINGKAT HUNIAN KAMAR

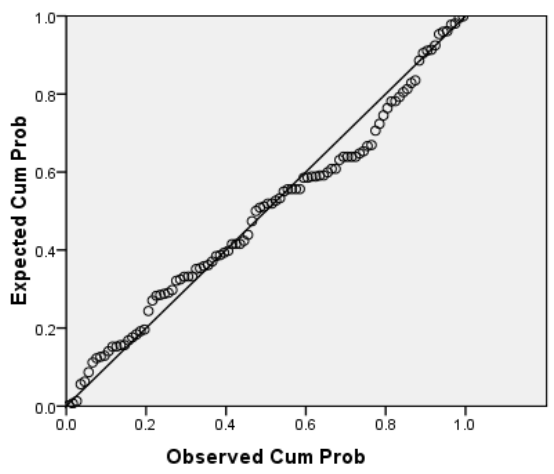

Sumber : Data Primer (diolah), 2019

Gambar 3 Grafik Normal P-Plot

Dari Gambar 3 menunjukkan bahwa data (titik) menyebar di sekitar garis normal dan mengikuti arah garis diagonal atau grafik Normal Probabilty Plot menunjukkan pola distribusi normal.

Tabel 3. Uji Statistik Untuk Normalitas

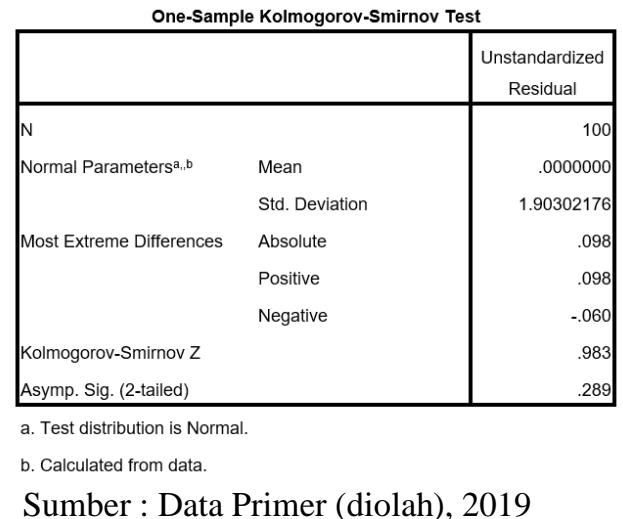

Berdasarkan tabel 3 di atas, maka dapat diketahui nilai signifikan lebih besar dari 0,05 yaitu sebesar 0,289. Hasil pengujian ini menunjukkan bahwa data berdistribusi normal. 


\section{Uji Multikolinearitas}

Tabel 4. Uji Multikolinearitas Coefficients $^{\mathrm{a}}$

\begin{tabular}{|ll|r|c|}
\hline \multicolumn{2}{|c|}{} & \multicolumn{2}{c|}{ Collinearity Statistics } \\
\cline { 3 - 4 } Model & & Tolerance & \multicolumn{1}{c|}{ VIF } \\
\hline $1 \quad$ (Constant) & & \\
& HARGA & .879 & 1.138 \\
& ONLINE CUSTOMER & .670 & 1.493 \\
& REVIEW & & \\
FASILITAS & .673 & 1.485 \\
\hline
\end{tabular}

a. Dependent Variable: TINGKAT HUNIAN KAMAR

Sumber : Data primer (diolah), 2019

Dari tabel 4 diketahui nilai Tolerance yang diperoleh dari variabel Harga adalah 0,879 yang lebih dari 0,10 dan nilai VIF yang diperoleh adalah 1,138 yang kurang dari 10 , nilai Tolerance yang diperoleh dari variabel Online Customer Review adalah 0,670 yang lebih dari 0,10 dan nilai VIF yang diperoleh adalah 1,493 yang kurang dari 10, nilai Tolerance yang diperoleh dari variabel Fasilitas adalah 0,673 yang lebih dari 0,10 dan nilai VIF yang diperoleh adalah 1,485 yang kurang dari 10 , sehingga dapat dinyatakan tidak terjadi persoalan multikolinearitas dengan variabel bebas lainnya.

\section{Uji Heteroskedastisitas}

Scatterplot

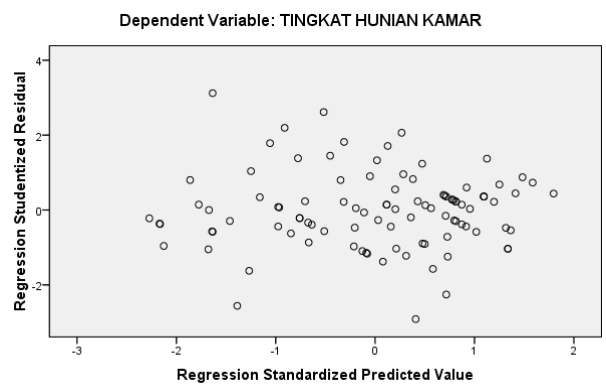

Sumber : Data Primer (diolah), 2019

Gambar 4. Grafik Scatterplot

Berdasarkan Gambar 4 terlihat titik-titik secara acak atau tidak membentuk suatu pola tertentu yang jelas secara tersebar baik di atas maupun di bawah angka 0 pada sumbu Regression Studentized Residual (Y). Hal ini berarti tidak terjadi heteroskedasitas pada model regresi sehingga model regresi ini layak digunakan untuk memprediksi Tingkat Hunian.

\section{Hasil Analisis Regresi Linear Berganda}

Tabel 5. Standardized Coefficients

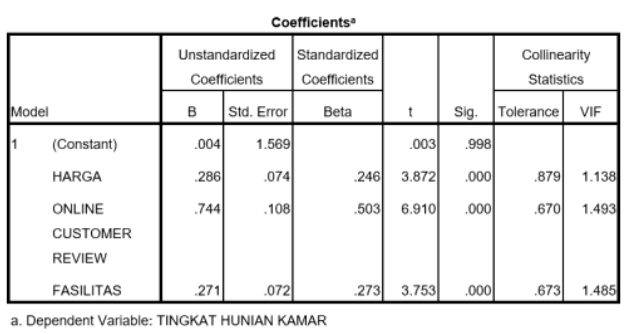

Sumber : Data Primer (diolah), 2019

Dari tabel 5, uji regresi linear berganda diperoleh persamaan regresinya adalah:

Tingkat Hunian $=0,004+0,286$ Harga + 0,744 Online Customer Review + 0,271 Fasilitas+e

Penjelasan persamaan sebagai berikut:

1. 0,004 artinya: jika Tingkat Hunian yang diteliti konstan, maka Tingkat Hunian pada PT. Karya Cipta Pesona (Aryaduta Medan) adalah sebesar 0,004 .

2. 0,286 artinya jika setiap penambahan satu-satuan variabel Harga $\left(\mathrm{X}_{1}\right)$ akan menyebabkan Tingkat Hunian bertambah sebesar 0,286 satu-satuan dengan kondisi faktor variabel Online Customer Review $\left(\mathrm{X}_{2}\right)$ dan Fasilitas $\left(\mathrm{X}_{3}\right)$ dianggap konstan.

3. 0,744 artinya jika setiap penambahan satu-satuan variabel Online Customer Review $\left(\mathrm{X}_{2}\right)$ akan menyebabkan Tingkat Hunian bertambah sebesar 0,744 satu-satuan dengan kondisi faktor variabel Harga $\left(\mathrm{X}_{1}\right)$ dan Fasilitas $\left(\mathrm{X}_{3}\right)$ dianggap konstan.

4. 0,271 artinya jika setiap penambahan satu-satuan variabel Fasilitas $\left(\mathrm{X}_{3}\right)$ akan menyebabkan Tingkat Hunian 
bertambah sebesar 0,271 satu-satuan dengan kondisi faktor variabel Harga $\left(\mathrm{X}_{1}\right)$ dan Online Customer Review $\left(\mathrm{X}_{2}\right)$ dianggap konstan.

\section{Hasil Pengujian Hipotesis Uji t (Uji Parsial)}

Uji t digunakan untuk melihat secara parsial apakah ada pengaruh yang signifikan dari variabel bebas terhadap variabel terikat. Bentuk pengujiannya adalah sebagai berikut:

1. $\mathrm{H}_{0}: \beta_{1}, \beta_{2}, \beta_{3}=0$, Artinya Harga; Online Customer Review; Fasilitas secara parsial tidak berpengaruh terhadap Tingkat Hunian pada PT. Karya Cipta Pesona (Aryaduta Medan).

2. $\mathrm{H}_{1}: \beta_{1}, \beta_{2}, \beta_{3} \neq 0$, Artinya Harga; Online Customer Review; Fasilitas secara parsial berpengaruh terhadap Tingkat Hunian pada PT. Karya Cipta Pesona (Aryaduta Medan).

Tabel 6. Uji Parsial

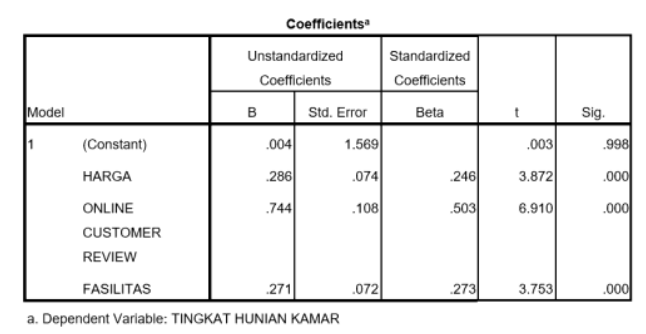

Sumber : Data Primer (diolah), 2019

Dari tabel 6, diperoleh Nilai $t_{\text {hitung }}$ untuk variabel Harga adalah 3,872 dengan tingkat signifikan 0,000 . Dengan derajat bebas (df) sebesar 98 (n-2 $=100$ orang responden - 2) dan taraf sig $\alpha=5 \%$ maka nilai $t_{\text {tabel }}$ adalah sebesar 1,984 . Oleh karena nilai $t_{\text {hitung }}>t_{\text {tabel }}$ maka kriterianya adalah $\mathrm{H}_{0}$ ditolak, $\mathrm{H}_{1}$ diterima sehingga Harga secara parsial berpengaruh positif dan signifikan terhadap Tingkat Hunian pada PT. Karya Cipta Pesona (Aryaduta Medan), Nilai $t_{\text {hitung }}$ untuk variabel Online Customer Review adalah 6,910 dengan tingkat signifikan 0,000. Dengan derajat bebas (df) sebesar $98 \quad(\mathrm{n}-2=100$ orang responden - 2) dan taraf $\operatorname{sig} \alpha=5 \%$ maka nilai $t_{\text {tabel }}$ adalah sebesar 1,984 . Oleh karena nilai $t_{\text {hitung }}>t_{\text {tabel }}$ maka kriterianya adalah $\mathrm{H}_{0}$ ditolak, $\mathrm{H}_{1}$ diterima sehingga Online Customer Review secara parsial berpengaruh positif dan signifikan terhadap Tingkat Hunian pada PT. Karya Cipta Pesona (Aryaduta Medan), dan Nilai thitung untuk variabel Fasilitas adalah 3,753 dengan tingkat signifikan 0,000 . Dengan derajat bebas (df) sebesar 98 (n-2 $=100$ orang responden -2 ) dan taraf sig $\alpha=5 \%$ maka nilai $t_{\text {tabel }}$ adalah sebesar 1,984. Oleh karena nilai $t_{\text {hitung }}>t_{\text {tabel }}$ maka kriterianya adalah $\mathrm{H}_{0}$ ditolak, $\mathrm{H}_{1}$ diterima sehingga Fasilitas secara parsial berpengaruh positif dan signifikan terhadap Tingkat Hunian pada PT. Karya Cipta Pesona (Aryaduta Medan).

\section{Uji F (Uji Simultan)}

Uji $F$ pada dasarnya menunjukkan apakah semua variabel bebas yang dimasukkan dalam model mempunyai pengaruh secara simultan terhadap variabel dependen. Uji F digunakan untuk menguji pengaruh dimensi variabel bebas secara serempak terhadap variabel terikat. Bentuk pengujiannya adalah sebagai berikut:

1. $\mathrm{H}_{0}: \beta_{1}, \beta_{2}, \beta_{3}=0$, Artinya Harga, Online Customer Review dan Fasilitas secara serempak tidak berpengaruh terhadap Tingkat Hunian pada PT. Karya Cipta Pesona (Aryaduta Medan).

2. $\mathrm{H}_{1}: \beta_{1}, \beta_{2}, \beta_{3} \neq 0$, Artinya Harga, Online Customer Review dan Fasilitas secara serempak berpengaruh terhadap Tingkat Hunian pada PT. Karya Cipta Pesona (Aryaduta Medan). 
Tabel 7. Uji Simultan

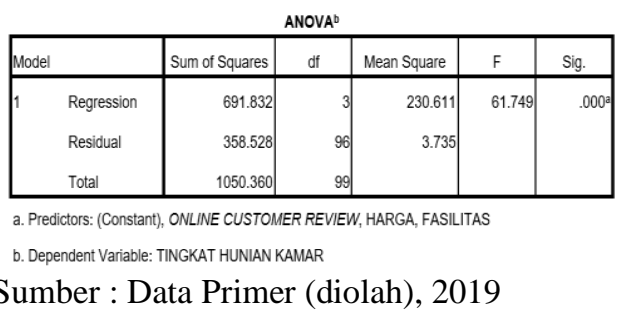

Berdasarkan tabel 7 diketahui nilai $F_{\text {hitung }}$ sebesar 51,284 dengan tingkat signifikan 0,000. Untuk tingkat keyakinan $95 \%, \mathrm{df}_{1}=3$, dan $\mathrm{df}_{2}=96$ maka nilai $\mathrm{F}_{\text {tabel }}$ adalah 2,70. Oleh karena $\mathrm{F}_{\text {hitung }}>\mathrm{F}_{\text {tablel }}$ maka kriterianya adalah $\mathrm{H}_{0}$ ditolak $\mathrm{H}$ diterima sehingga dapat dinyatakan bahwa Harga, Online Customer Review dan Fasilitas secara serempak berpengaruh dan signifikan terhadap Tingkat Hunian pada PT. Karya Cipta Pesona (Aryaduta Medan).

\section{Koefisien Determinasi $\left(\mathbf{R}^{2}\right)$}

Koefisien determinasi $\left(\mathrm{R}^{2}\right)$ pada intinya mengukur seberapa jauh kemampuan model dalam menerangkan variasi variabel dependen.

Tabel 8. Uji Koefisien Determinasi

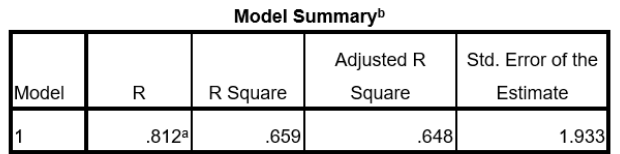

a. Predictors: (Constant), ONLINE CUSTOMER REVIEW, HARGA, FASILITAS

b. Dependent Variable: TINGKAT HUNIAN KAMAR

Sumber : Data Primer (diolah), 2019

Dari tabel 8, diperoleh bahwa koefisien determinasi Adjusted $R$ Square adalah 0,648. Hal ini menunjukkan bahwa $64,8 \%$ Tingkat Hunian pada PT. Karya Cipta Pesona (Aryaduta Medan) dipengaruhi oleh variabel Harga, Online Customer Review dan Fasilitas, sedangkan $34,1 \%$ dipengaruhi oleh variabel-variabel lainnya yang tidak diteliti dalam penelitian ini.

\section{Pembahasan Hasil Penelitian}

Hasil uji koefisien determinasi $\left(\mathrm{R}^{2}\right)$ menunjukkan bahwa nilai Adjusted $R$ Square yang diperoleh adalah 0,648 yang berarti $64,8 \%$ variabel Tingkat Hunian dipengaruhi oleh variabel kepercayaa, Online Customer Review dan Fasilitas, sedangkan sisanya sebesar $35,2 \%$ dipengaruhi oleh variabel-variabel lainnya yang tidak diteliti dalam penelitian ini.

Hasil Uji t menunjukkan bahwa Harga secara parsial memiliki pengaruh positif dan signifikan terhadap Tingkat Hunian pada PT. Karya Cipta Pesona (Aryaduta Medan) karena nilai $t_{\text {hitung }}$ sebesar 3,872 lebih besar dari nilai $t_{\text {tabel }}$ yang sebesar 1,984. Hasil penelitian ini tidak sesuai dengan penelitian yang dilakukan Ilham Labbase (2015) yang menemukan bahwa

1. penetapan harga berpengaruh negative dan signifikan terhadap kepuasan pelanggan pada Hotel Horison Makassar. Tetapi penelitain ini sesuai dengan Andri Wijiatmoko (2016) yang mengemukakan ada pengaruh positif harga terhadap keputusan menginap di Hotel Syariah Surakarta, dan Nicklouse Christian Lempoy (2015) menemukan dalam penelitiannya bahwa harga berpengaruh signifikan dalam menggunakan jasa Taman Wisata Toar Lumimuut Sonder.

1. Hasil Uji t menunjukkan bahwa Online Customer Review secara parsial memiliki pengaruh positif dan signifikan terhadap Tingkat Hunian pada PT. Karya Cipta Pesona (Aryaduta Medan) karena nilai $t_{\text {hitung }}$ sebesar 6,910 lebih besar dari nilai $t_{\text {tabel }}$ yang sebesar 1,984. Hasil penelitian ini sesuai dengan Nur Dan Mirza (2018), yang menemukan bahwa Online consumer reviews berpengaruh signifikan terhadap keputusan pembelian Shoppee di Surabaya. 
Hasil Uji t menunjukkan bahwa Fasilitas secara parsial memiliki pengaruh positif dan signifikan terhadap Tingkat Hunian pada PT. Karya Cipta Pesona (Aryaduta Medan) karena nilai thitung sebesar 3,753 lebih besar dari nilai $t_{\text {tabel }}$ yang sebesar 1,984. Penelitian ini sesuai dengan Nicklouse Christian Lempoy (2015) yang menemukan bahwa Fasilitas secara parsial berpengaruh signifikan terhadap keputusan menggunakan jasa Taman Wisata Toar.

Hasil Uji F menunjukkan bahwa Harga, Online Customer Review dan Fasilitas secara serempak berpengaruh terhadap Tingkat Hunian pada PT. Karya Cipta Pesona (Aryaduta Medan) karena nilai $F_{\text {hitung }}$ sebesar 61,749 lebih besar dari $F_{\text {tabel }}$ yang sebesar 2,70. Penelitian ini sejalan dengan Nicklouse Christian Lempoy (2015) yang menemukan bahwa Harga, Lokasi, dan Fasilitas secara simultan berpengaruh signifikan terhadap Keputusan Menggunakan jasa Taman Wisata Toar Lumimuut Sonder

\section{PENUTUP}

\section{Kesimpulan}

Kesimpulan dalam penelitian ini adalah:

1. Harga yang variatif memiliki pengaruh positif dan signifikan terhadap Tingkat Hunian pada PT. Karya Cipta Pesona (Aryaduta Medan)

2. Online Customer Review memiliki pengaruh positif dan signifikan terhadap Tingkat Hunian pada PT. Karya Cipta Pesona (Aryaduta Medan)

3. Fasilitas secara parsial memiliki pengaruh positif dan signifikan terhadap Tingkat Hunian pada PT. Karya Cipta Pesona (Aryaduta Medan)

4. Harga, Online Customer Review dan Fasilitas secara serempak berpengaruh terhadap Tingkat Hunian pada PT. Karya Cipta Pesona (Aryaduta Medan)

\section{Saran}

Di lihat dari besarnya pengaruhnya Harga, Online Customer Review, dan Fasilitas yaitu 64,8\% terhadap Tingkat Hunian pada PT. Karya Cipta Pesona (Aryaduta Medan), pihak manajemen dapat mempertahankan dan meningkatkan ketiga variabel tersebut untuk peningkatan hunian, dan pihak manajemen juga dapat mempertimbangkan variabel lainnya yang mempengaruhi secara signifikan terhadap peningkatan hunian seperti

Online Customer Rating, dan Promosi.

\section{DAFTAR PUSTAKA}

Agus, Sulastiyono. 2011. Manajemen Penyelenggaraan Hotel : Manajemen Hotel. Bandung ; Alfabeta.

Cunningham et al. 2010. Does Tripadvisor Make Hotel Better?

Damardjati, R.S. 2006. Istilah-istilah Dunia Pariwisata. Jakarta : PT. Pradnya Paramita.

Farki, A. 2016. Pengaruh Online Customer Review dan Rating Terhadap Kepercayaan dan Minat Pembelian pada Online Marketplace di Indonesia.

Ghozali, Imam, 2009. Aplikasi Analisis Multivariate Dengan Program SPSS, Edisi. Keempat, Penerbit Universitas Diponegoro.

Gretzel, Ulrike. 2007. Travel Review Study : Role \& Impact of Online Travel Reviews.

Hanggara, Vicky. 2009. Pengertian Tingkat Hunian Hotel. (http://vickyhanggara.blogspot.c 
o.id/2009/05/pengertian-tingkat-

huniankamarhotel.html)

Ichsan, Masyita. 2018. Pengaruh Consumer Online Rating dan Review terhadap Minat Beli Konsumen pada Marketplace Tokopedia di Wilayah DKI Jakarta.

Kotler, Philip. 2005. Manajemen Pemasaran. Jilid I dan II. Jakarta. PT. Indeks dan Kevin Lane Keller. 2009. Manajemen Pemasaran. Jilid I. Edisi ke 13. Jakarta ; Erlangga dan Gary Amstrong. 2012. Prinsip-prinsit Pemasaran. Edisi 13. Jilid 1. Jakarta ; Erlangga.

Kusuma, Rizal Wahyu. 2015. Pengaruh Kualitas Produk, Harga, Fasilitas dan Emosional terhadap Kepuasan Pelanggan.

Labbase, Ilham. 2015. Pengaruh Penetapan Harga dan Kualitas Layanan Terhadap Kepuasan Pelanggan pada Hotel Horison Kota Medan.
Lempoy, N.C. 2015. Pengaruh Harga, Lokasi, dan Fasilitas terhadap Keputusan Menggunakan Jasa Taman Wisata Toar Lumimuut (Taman Eman Sonder).

Sugiarto, Endar. 2004. Hotel Front Office Administration (Administrasi Kantor Depan Hotel). Jakarta ; Gramedia Pustaka Utama.

Sugiyono. 2008. Metode Penelitian Bisnis. Bandung : Alfabeta.

Swastha, Basu. 2010. Manajemen Penjualan : Pelaksanaan Penjualan. Yogyakarta ; BPFE

Tjiptono, Fandy. 2008. Strategi Pemasaran. Edisi 3. ANDI: Yogyakarta.

Vermuelen dan Seegers. 2009. Tried and tested : The impact of online hotel reviews on consumer consideration.

Wijiatmoko, Andri. 2016. Analisis Pengaruh, Harga, Kualitas Pelayanan, dan Lokasi. 